\title{
O sintoma entre a terapêutica e o incurável: uma leitura lacaniana
}

\author{
Cristina Moreira Marcos* \\ Ednei Soares de Oliveira Junior**
}

\section{Resumo}

$\mathrm{O}$ artigo a seguir trata das relaçóes entre a possibilidade terapêutica do tratamento psicanalítico e o núcleo incurável contido no sintoma tal como este foi definido pela psicanálise a partir das orientaçóes contidas na obra de Freud e no ensino de Lacan. Ao final da obra de Freud, o resto irredutível do sintoma deixou-lhe um impasse sobre o destino oferecido a esse resíduo no tratamento psicanalítico. $\mathrm{O}$ ensino de Lacan por sua vez, não recuou frente a esse impasse. Ao considerar a importância do sintoma em psicanálise, Lacan evidencia que ele tem uma função para o sujeito e não se trata de eliminá-lo. Desse modo, o psicanalista francês apresentou fundamentos que dão outros destinos ao resto não eliminável na experiência analítica. Assim, a abordagem lacaniana do sintoma demarca os limites da eficácia terapêutica da psicanálise, pois tais limites derivam, justamente, do elemento incurável que se impóe na experiência analítica.

Palavras-chave: sintoma; terapêutica; incurável; Lacan.

\begin{abstract}
THE SYMPTOM BETWEEN THERAPEUTIC AND THE INCURABLE: A LACANIAN READING

The following article deals with the relationship between the therapeutic possibilities of psychoanalytic treatment and the incurable factor contained in the symptoms as defined by psychoanalysis according to Freud's and Lacan's work. At the end of Freud's work, the irreducible

\footnotetext{
* Pontifícia Universidade Católica de Minas Gerais, Belo Horizonte, MG, Brasil.

** Centro Universitário UMA, Belo Horizonte, Belo Horizonte, MG, Brasil; Faculdades Pitágoras de Ipatinga, Ipatinga, MG, Brasil.
} 
residue of the symptom left him a deadlock about it's destiny in psychoanalytic treatment. On this issue the Lacanian teaching did not retreat. When considering the importance of the symptom in psychoanalysis, Lacan shows that the symptom has a role to the subject and must not be eliminate. Thus, the French psychoanalyst had presented fundamentals to give destination to this non-eliminable rest in the analytic experience. Lacan's conception of the symptom marks the limits of therapeutic effectiveness. These limits are related to the incurable element found in psychoanalysis.

Keywords: symptom; therapeutic; incurable; Lacan.

\section{Resumen}

EL SÍNTOMA ENTRE LA TERAPÉUTICA Y EL INCURABLE: UNA LECTURA LACANIANA

El texto trata de la relación entre la posibilidad terapéutica del tratamiento psicoanalítico y el núcleo incurables de los síntomas como se define por el psicoanálisis de Freud y de Lacan. Al final de la obra de Freud, el síntoma incurable dejó un punto muerto sobre el destino que ofrece este residuo en el tratamiento psicoanalítico. La enseñanza de Lacan, a su vez, no dio marcha atrás frente a este impasse. Al considerar la importancia del síntoma en psicoanálisis, Lacan muestra que tiene un papel en el sujeto y no es para eliminarlo. Por lo tanto, el psicoanalista francés presentó fundamentos que dan otros destinos al resto ineludible en la experiencia analítica.

Palabras clave: síntoma; terapéutica; incurable; Lacan.

Partiremos do fato de que, enquanto método de tratamento, a psicanálise produz efeitos terapêuticos. Freud jamais abandonou tal perspectiva (1932/1976). Entretanto os sintomas dos pacientes de Freud lhe apresentaram uma trama de elementos delineadores de um núcleo que se opóe à cura durante o tratamento. Haveria aqui então um paradoxo: se é devido ao sintoma que alguém procura um tratamento, seu núcleo não poderá ser desfeito completamente em análise.

Ao longo da obra freudiana, a tensão entre a dimensão terapêutica da psicanálise e a irredutibilidade do sintoma foi elaborada através de descobertas clínicas e torçóes teóricas que modificaram as expectativas do tratamento psicanalítico. Elementos como resistência, compulsão à repetição e pulsão de morte terão implicaçáo sobre como se dá o tratamento do sintoma em psicanálise.

Apesar do entusiasmo declarado pela eficácia terapêutica da psicanálise, Freud (1937/1976), ao final de sua obra, náo deixa de reconhecer os resíduos e restos sintomáticos que o viés terapêutico de seu método não conseguiria supri- 
mir. O resto irredutível do sintoma com que Freud se deparou deixou-lhe um impasse em relaçáo ao destino que poderia ser oferecido a esse resíduo no tratamento analítico. Nessa medida, Freud concebeu a análise como interminável. Veremos que o ensino de Lacan, por sua vez, apresentou fundamentos importantes para dar destino a esse resto irrepresentável e não eliminável da experiência analítica, tecendo assim outros modos de equacionar a coexistência entre expectativa terapêutica e o elemento não eliminável do sintoma.

Se Freud apresentou, em seu primeiro momento, um entusiasmo convertido posteriormente em cautela sobre o terapêutico na psicanálise, sobretudo para distingui-la como prática singular, não encontramos em Lacan simpatia ou entusiasmo algum, por assim dizer, pela temática da terapêutica. Isso não significa que Lacan desconsidera as relaçóes entre o terapêutico e a psicanálise.

O "retorno a Freud" empreendido por Lacan denunciou os descaminhos da prática analítica, precisamente quanto a uma finalidade de eficácia terapêutica que ela havia ganhado. Se a psicanálise, segundo Lacan, tem um campo específico, nele o cuidado terapêutico a desvia de seu próprio campo, causando até mesmo curtos-circuitos. Para o próprio Lacan (1966/1998c), trata-se de impedir que o campo psicanalítico sofra qualquer redução similar.

De todo modo, as transformaçóes que Lacan produziu sobre o domínio da práxis psicanalítica e a fecundidade de um novo ângulo para a abordagem dedicada ao sintoma não dissolveram a tensão entre experiência analítica e seus efeitos terapêuticos. Lacan (1936/1998f) considerou o fato de que o elemento da terapêutica constitui a experiência analítica, entretanto ele afirma que é necessário senso teórico para definir o que essa terapêutica produz. $\mathrm{Na}$ verdade, podemos dizer que, em Lacan, não há uma rejeição ao elemento terapêutico, mas considera-se o fato de que a psicanálise não é uma terapêutica como as outras (Lacan, 1958/1998a).

Alain Merlet (1998) afirma que, embora não exista em Lacan um entusiasmo pela terapêutica, ele jamais se dedicou a denegrir este campo sistematicamente. Para Lacan, a prática de Freud caracterizava-se como a última flor da medicina. Uma espécie de medicina do humano afligido pela linguagem. Ou seja, podemos atribuir a Lacan o fato de ter dissipado a definição que fazia com que a cura se confundisse com a terapêutica.

Devemos considerar que o termo cura utilizado por Lacan não designa propriamente a eliminação de um mal. $\mathrm{O}$ uso lacaniano da palavra francesa cure significa, sobretudo, "tratamento, análise ou tratamento analítico" (Lacan, 1998d, p. 936). Ou seja, Lacan amarra sua teia conceitual ao fato de que ela é intrínseca a um tratamento: 
A psicanálise, no entanto, distinguiu-se a princípio por dar acesso à ideia de cura em seu campo, ou seja: dar aos sintomas seu sentido, dar lugar ao desejo que eles mascaram, retificar de modo exemplar a apreensão de uma relação privilegiada - ainda que tivesse sido preciso poder ilustrar isso com distinçóes estruturais exigidas pelas formas da doença, reconhecê-las nas relaçooes do ser que demanda e que se identifica com essas próprias demanda e identificação (Lacan, 1964/2003a, p. 245).

Entretanto é preciso dizer que a ênfase que Lacan dá à dimensão do sintoma lhe oferece voz, ao invés de eliminá-lo num viés terapêutico. Enfim, o sintoma em psicanálise, muito embora nos seja apresentado como um problema, não é tratado como algo que deva ser arrancado do paciente e nem silenciado (Laia, 2008).

Em seu desígnio de extinguir um mal, obtendo aí sua eficácia, a terapêutica representa a intenção de recuperar a nostalgia de um momento sem sintomas, sem problemas. Contudo, a experiência analítica reconhece que o sintoma deixa restos. Nesse sentido, temos a observação categórica de Lacan: "Observaria eu, com efeito, que não há definição possível da terapêutica senão a de restabelecimento de um estado primário. Definição, justamente, impossível de enunciar na psicanálise” (Lacan, 1967/2003b, p. 251). O tratamento analítico, ou cura analítica, tem de fato outra aspiração, pois interroga aspectos correlacionados a uma suposta restauração da condição original e aponta para o próprio incurável em jogo.

\section{Trata-se do sintoma}

Se a semiologia médica, disciplina que consagrou o termo "sintoma", implica-o como modo de afirmar a doença através da percepção subjetiva do paciente sobre seus distúrbios, incômodos ou dores (Forns, Batlo \& Batllo, 1981), a psicanálise dará ao sintoma um estatuto diferente, mas sem furtar-se de considerá-lo um problema. Na clínica médica, em seu compromisso terapêutico primordial, o sintoma significa algo que não vai bem, algo anormal, bizarro, uma alteração de função ou alerta de doença. Isto é, alguma maneira de o paciente se perceber como um possível doente (Ferreira \& Pimenta, 2003). Se o sintoma tem como significado uma doença, consequentemente o que se aspira é sua eliminação pura e simples (Ferreira \& Pimenta, 2003).

O sintoma, em Lacan, se alia à metáfora do "umbral", ou seja, aquilo que leva alguém a entrar na análise, implicando o sujeito em uma busca provocada pelo sofrimento. Colette Soler (1998a) sublinha que o analisante, de fato, dirige-se à análise 
em nome de seu sofrimento, porque nele há um sintoma. Podemos reconhecer aqui esse ponto de convergência da psicanálise com a terapêutica na medida em que é a partir da constatação de "algo vai mal" que se procura uma análise, ou, segundo Miller (1997): "O sintoma produz a dimensão da terapêutica” (Miller, 1997, p. 162). Em Lacan (1936/1998f), o sintoma constitui o elemento da terapêutica em psicanálise. Dito de outro modo, em sua função de entrada no tratamento analítico o sintoma clama por uma ação terapêutica. Daí a afirmativa lacaniana (1965-66) de que temos, como analistas, que tomar parte no sintoma.

Mesmo que a psicanálise abrigue o sintoma em outro campo conceitual, dando-lhe um estatuto diferente daquele de impulsionar a evolução da terapêutica, Lacan náo sacrifica a consideração de que se trata do sintoma na experiência analítica. Não abdicando ao sintoma, e colocando-o como ponto central da experiência psicanalítica, Lacan distancia essa experiência de qualquer espécie de autoconhecimento, aventura intelectual ou filosófica. Aliás, contra essa última, Lacan se insurge, rejeitando-a (Lacan, 1980).

O sintoma, portanto, configura o campo de atuação da psicanálise. Ora, desde a década de 1950 encontramos a orientação de Lacan de que o que constitui o campo analítico é o sintoma. (Lacan, 1955-56/1988). Longe de dissipá-lo da experiência analítica, o analista é aquele que recebe e suporta o estatuto do sintoma (Lacan, 1964-65). Prova de que Lacan não se esquiva de estabelecer a experiência psicanalítica como um tratamento.

Embora a causa do tratamento psicanalítico não seja uma aspiração de eliminação pura do sintoma, uma vez que ele constitui o campo psicanalítico, evidencia-se certa coexistência do componente terapêutico na experiência analítica, pois tampouco se trata da manutenção do sofrimento causado pelo sintoma, já que ele não deixa de ser potencialmente um problema (Laia, 2008). Encurtando a distância entre aquilo que clama por algum alívio e aquilo que não deve ser eliminado, a tensão entre terapêutico e analítico se entrevê.

Merlet (1998) nos faz recordar que em análise não pode haver nem restitutio ad integrum, nem respeito absoluto à máxima Primum non nocere, pois existe $\mathrm{o}$ incurável. Essa afirmativa nos indica que, num tratamento analítico, não se trata de restaurar nenhuma condição original (Primum non nocere) e nem de fazer valer a máxima do "acima de tudo, não prejudicar" (Primum non nocere), pois o sujeito terá de se haver com seu sintoma. Contudo, trata-se de interrogá-lo. Isto é, ainda que o sintoma conduza à análise, faz-se necessário que aquele que o porta articule um questionamento a respeito daquilo sobre o que se queixa.

Tendo em vista a orientação lacaniana de manter a experiência analítica fora dos efeitos da demanda (Lacan, 1958/1998h) de modo a interrogá-la, 
em "Televisão" (1973/2003c) veremos Lacan considerar a cura, justamente, como uma demanda: "A cura é uma demanda que parte da voz do sofredor, de alguém que sofre de seu corpo ou seu pensamento" (Lacan, 1973/2003c, p. 511).

Se o analista deve tomar parte no sintoma e suportar seu estatuto, sua posição deve suscitar a implicação do sujeito em seu sintoma. Isto é, o analista deve retornar para o sujeito formulando um Che vuoi? - (o que você quer?) (Lacan, 1960/1998g). Nessa interrogação, a análise não elimina o sintoma, mas o complementa: "a práxis psicanalítica é literalmente o complemento do sintoma. [...] pela apreensão de uma certa perspectiva, de uma certa maneira de interrogar o sofrimento neurótico que, efetivamente, completa-se na cura, a sintomatologia” (Lacan, 1965-66).

A consideração sobre o sintoma como um enigma a ser interrogado também já constituía a orientação de Lacan (1956-57/1995) desde a década de 1950. Contudo, mais tarde, Lacan (1966-67) afirmará que o caráter enigmático do sintoma revela uma opacidade subjetiva. $\mathrm{O}$ elemento enigmático no sintoma certamente revela um estatuto de opacidade, dada a presença de seu resto irredutível que não se entrega à terapêutica ou mesmo à interrogaçáo sobre o sintoma. Em Lacan, esse questionamento procura reconhecer a que esse sintoma responde como modo de gozo que ele circunscreve. Portanto, essa opacidade, nomeada por Lacan como gozo, revela a satisfação inconsciente no sintoma, sobre a qual não é possível extrair uma decifração.

Todavia, sabemos que o ensino de Lacan percorreu uma vertente caracterizada pela fidelidade ao invólucro formal do sintoma (Lacan, 1966/1998b). Nesse período, ao dar primazia ao simbólico em seu ensino, Lacan tomou o sintoma definido como uma mensagem a ser decifrada por ser ele mesmo estruturado como uma linguagem (Lacan, 1953/1998e), já que o sintoma está sempre fundado na existência do significante. Nesse viés, Lacan examinou cuidadosamente o milagre que o psicanalista operaria pela via simbólica, ou seja, o desaparecimento do sintoma via sua mera interpretação.

Entretanto, concentrar-nos-emos no fato de que o ensino de Lacan abordará o sintoma para além de seu envelope formal composto por significantes e tomado como símbolo. Nessa perspectiva, o sintoma será considerado como sendo constituído por um núcleo de gozo. Esse núcleo, não decifrável pela interpretação, é aquele da opacidade subjetiva e que mais tarde Lacan trataria como o núcleo do caráter enigmático do sintoma (Lacan, 1966-67).

Toda essa temática a respeito do sintoma adquire relevância para Lacan na medida em que ele realiza elaboraçóes inéditas sobre as possibilidades do tratamento analítico face ao incurável com que Freud se deparou. 


\section{Sintoma e gozo: sofrimento e satisfaçáo}

Desde a formulação freudiana sobre a pulsão de morte (Freud, 1920/1976), revelou-se que há invariavelmente uma satisfação, seja numa experiência prazerosa, seja numa experiência de sofrimento. Freud considera que algo se satisfaz no sintoma por mais doloroso que este seja e sem que o sujeito o saiba (Soler, 1998b).

Segundo Fink (1998), o termo jouissance se relaciona ao prazer, mas também à dor, ao horror e ao nojo. Lacan estará atento a essa questão, sobretudo no que tange ao sintoma, pois os sintomas dependem da satisfação (Lacan, 1964/1973). Sobre as relações entre sintoma e satisfação, Soler (1998c) esclarecerá, dizendo que as pulsões nunca renunciam, e a pulsão, quando contida, leva a satisfazer-se na produção de sintomas. A satisfação pulsional atualizada no sintoma fará com que Lacan reconheça, entáo, o sintoma como um modo de gozo.

Quer dizer que gozo pode ser tanto o prazer quanto o sofrimento e que Lacan especializou progressivamente este termo "gozo" para qualificar a satisfação dita inconsciente, a satisfação da qual não se sabe (Miller, 2005). Enfim, Lacan retomou Freud nesse viés justamente para afirmar que a função do sintoma é gozo (Lacan, 1965-66).

Ainda é preciso dizer que a libido freudiana conserva as formas arcaicas que têm caráter irredutível, que náo se deixam dialetizar ou substituir pelo jogo dos significantes. Em relaçáo ao tratamento do sintoma na vertente de seu invólucro formal, pressupóe-se que a ordem simbólica, o significante, poderia moderar o gozo, domesticá-lo, reduzi-lo e/ou regulá-lo pelo viés de sua representação significante, mas há um resto que não se deixa regular pela representação significante (Miller, 2005).

Uma vez que o gozo incluído no sintoma não se deixa simbolizar, vemos que ele se relaciona com a dimensão do Real em jogo em uma análise. Se a categoria de Real no ensino lacaniano ganha o estatuto daquilo que não pode ser redutível ao simbólico, Lacan afirma, nesse sentido, que o sintoma é Real (Lacan, 1974-75).

Verificam-se, então, os motivos que levariam Lacan (1964/1973) a colocar o Real na centralidade da práxis analítica e afirmar que a prática analítica permite cernir aquilo que do gozo sintomático se refere ao Real (Lacan, 1968-69/2008). Portanto, o gozo incluído no sintoma delimita algo excluído da dimensão simbólica, uma vez que se pode chamar de Real o que está fora do simbólico. Real este excluído das chances de eficácia terapêutica pela dimensão simbólica: "É justamente a isso que se liga nossa prática - ali onde devemos lidar com o sintoma, 
desvelar, desmascarar a relação com o gozo, que é nosso Real, uma vez que está excluído" (Lacan, 1968-69/2008, p. 316).

A centralidade que o sintoma e sua relação com o Real ganham em psicanálise não esvazia a tensão entre o efeito terapêutico e o tratamento analítico. A entrada em análise se dá porque o sintoma se apresenta como um sofrimento e o sofrimento é também um modo de gozo. Por isso, justamente ao produzir gozo, o sintoma causa um desconforto ao sujeito. Daí a demanda pela terapêutica, ou, como afirma Lacan, a cura como uma demanda.

Dominique Fingermann (2005) recorda que o Real implicado no gozo possui sua face aterrorizante e traumática, nomeada por Lacan como "pior", e que a clínica psicanalítica o recolhe no tratamento. Este "pior”, segundo Fingermann (2005), é um campo de guerra, um campo de gozo que se manifesta no Real.

É valido lembrar a advertência de Lacan (1973/2003c) sobre o pior em relaçáo à psicoterapia, na medida em que ela promoveria um bem através da terapêutica. Para Lacan (1973/2003c), a psicoterapia, seja ela qual for, estancaria justamente no que tange ao gozo do sintoma não porque não exerça um certo bem, mas por ser um bem que leva ao pior. "Essas soluçôes retornam ao pior à medida que, tentando preservar o sujeito, colocando-o à distância do real, contribuem para debilitá-lo, deixando-o sem recursos ou desenvoltura frente às eventualidades inevitáveis de suas reviravoltas" (Fingermann, 2005, p. 55).

Ciente da impossibilidade de "terapeutizar" o Real, já que ele não se articula, a psicanálise não prevê uma solução que o apague. Trata-se, antes, do próprio sintoma como uma possibilidade de solução, pois o sintoma é um tratamento do Real. O sintoma no tratamento analítico se configura, então, como um modo de circunscrever, em seu invólucro formal, algo do Real que o compóe, o que daí possibilita o tratamento do pior pelo sintoma, pois o Real impossível de suportar não tem remédio, mas tem tratamento: o sintoma seria, então, um deles (Fingermann, 2005). Segundo Antônio Teixeira (2007a), essa problemática levou Freud a evidenciar aquilo que se refere à noção do sintoma como constituição de compromisso, ou seja, o viés peculiar de cada sujeito no tocante de seu sintoma.

Isso faz com que seja realmente difícil para o neurótico livrar-se de seu próprio sintoma, pois a relaçáo do sujeito com seu sintoma é sempre de uma tensão, uma tensão paradoxal, pois o sintoma é uma intenção de solucionar-lhe um conflito. Conforme explicita Sérgio Laia (2008), o sintoma é uma solução porque é uma resposta a um problema, a um obstáculo que a satisfação do neurótico encontrou.

No horizonte do caráter paradoxal da satisfaçáo implicada no sintoma, e considerando o sintoma como modo de gozo, tal fato coloca em relaçáo o sujeito 
e suas formas singulares de lidar com o Real aí em jogo. Ora, dado o paradoxo do gozo, vê-se que o sujeito no tratamento psicanalítico se sustenta não somente no sofrimento que o leva à análise, mas numa satisfação contida nesse sofrimento. Lacan nos dá prova disso quando afirma que o sujeito tem uma sustentação no sintoma e na satisfação aí produzida.

O sujeito é suspenso por uma série de modos ou estados de insatisfação; eis aqui o que por si mesmo justifica a introduçáo do termo gozo, que a todo instante, principalmente no sintoma, apresenta-se a nós como indiscernível do registro da satisfação, já que para nós o problema é saber como um nó, que não se sustenta mais que através de enfermidades e sofrimentos, é por onde se manifesta a instância da satisfação suspensa. É justamente onde o sujeito se sustenta (Lacan, 1966-67).

A citação acima admite um estatuto importante para considerar a problemática da terapêutica no tratamento psicanalítico. Apesar de o sintoma se apresentar no tratamento como uma demanda que deverá ser interrogada, a concepção que Lacan introduz ultrapassa tal dimensão, pois, embora contenha enfermidades e sofrimentos, o sujeito encontra no gozo do sintoma sua própria sustentação. Vemos, mais uma vez, que, em Lacan, o sintoma não é concebido como um fator exatamente homólogo ao sofrimento, que deve ser eliminado pela terapêutica.

A terapêutica, como ambição de eliminação do sintoma, não condiz com a orientação de Lacan, pois o sintoma tem uma função, a maneira como cada um sofre em sua relação com o gozo se dá pela função do sintoma (Lacan, 196869/2008). A partir dessa função, Soler (1998c) afirma que o mais interessante de um sujeito é seu sintoma, pois graças a ele um sujeito difere do outro. $\mathrm{O}$ sintoma é então um princípio de singularidade, um princípio de diferença.

A maneira particular como cada sujeito estabelece sua relaçáo com o gozo, recorda Soler (1998c), é fixada no sintoma pelo Real que ali se impóe. Se o Real é o que volta sempre ao mesmo lugar (Lacan, 1975/1985), ou o que não cessa de se escrever (Lacan, 1974-75), o sintoma, por sua relação com o gozo, tem, portanto, uma função. No seminário "RSI", Lacan (1974-75) elucidará dizendo que a função do sintoma é o modo singular como ele opera selvagemente. O que não cessa de se escrever no sintoma resulta daí. Por isso a sentença lacaniana de chamar de sintoma o que vem do Real.

O empenho de Lacan, com sua maneira de abordar a noção de sintoma sob novas perspectivas, faz entrever o modo como ele confere dignidade a esse resto pulsional evidenciado desde Freud. Sem recusá-lo, Lacan delimita aí a particu- 
laridade da psicanálise, pois acredita que, nesse resto, encontra-se a mais íntima relação do sujeito com seu desejo e seu modo de gozo. Para que, no decorrer de uma análise, o sujeito estabeleça maneiras menos penosas de se relacionar com o gozo na singularidade de seu sintoma, há necessidade de uma certa depuração do terapêutico (Laia, 2008). Desinvestido de um ideal de eficácia terapêutica, mas claramente decidido por fazer avançar a conceitualizaçáo de sintoma na clínica psicanalítica, Lacan se mostra inventivo e criador de orientaçóes importantes para o tratamento.

Do ponto de vista do sintoma, reconhecido como modo de gozo, o sujeito se satisfaz. O sintoma não é mais concebido como um problema, sendo assim Lacan orienta que o sujeito encontre uma forma de lidar com o sintoma que não o coloque no "campo de guerra" do gozo, que lhe permita obter, nessa relação, alguma paz com o aspecto irreconciliável da pulsão presente no gozo. Sem fazer guerra ao sintoma para reduzi-lo ou eliminá-lo, Lacan oferece outras formas de tratá-lo.

\section{Consideraçôes finais: soluçóes e saídas com o sintoma}

As contribuiçôes de Lacan são valiosas nesse aspecto, pois, mais do que nunca, a psicanálise tem sido praticada em contextos cada vez mais variados e convocada a dar respostas aos mais diversos impasses subjetivos. Uma vez que tais respostas se efetivam, sobretudo a partir dos efeitos terapêuticos produzidos pela psicanálise, a orientação de Lacan é norteadora justamente por conseguir manter a ação analítica fora do viés normalizador e alienante de um ideal terapêutico.

As formulaçóes lacanianas que acompanham a perspectiva de não supressão do sintoma estão presentes, sobretudo, na última parte do ensino de Lacan. Nesse momento, Lacan concebe o final de uma análise como uma possibilidade de o sujeito produzir "um saber fazer aí com o sintoma" (savoir-y-faire): "Saber lidar com seu sintoma, é isso o fim da análise” (Lacan, 1976-77).

Ainda que não nos concentremos neste trabalho nos meandros da abordagem lacaniana sobre o final da análise, é possível pensar que o interesse pelo sintoma e sua depuração num tratamento analítico oferece ao sujeito, ao invés de sua eliminação, a possibilidade de conhecer seu sintoma, saber fazer com ele, saber desvencilhar-se dele, saber manipulá-lo (Lacan, 1976-77). Enfim, a psicanálise é pensada então em um processo no qual o analisante poderá depurar seu próprio savoir faire com o sintoma. 
Fora de um campo estritamente formalista, Lacan inseriu a noção de Real no sintoma como aquilo que escapa à apreensão simbólica, indicando, assim, um saber se virar com o sintoma, saber se desembaraçar (se débrouiller) dele, saber se desvencilhar do sintoma, ou manipulá-lo de uma maneira menos penosa. Ao invés de conceituar esse saber lidar com o sintoma de forma predeterminada, Lacan inclui o dado do Real que escapa em vista da peculiaridade de cada sujeito em sua relação com seu sintoma. Isso implica o fato de que a fixação de gozo sintomática se dá na medida em que se trata de uma fixação singular, pois não há fixação universal do gozo de cada sujeito (Soler, 1998c).

Assim como Lacan havia afirmado que só se é responsável na medida de seu savoir-faire (Lacan, 1975-76/2005), Soler (1998b) acentua que, para além do enigma e do gozo implicados no sintoma, há uma responsabilidade do sujeito, uma vez que a posição tomada frente ao gozo é determinante. A perspectiva do savoir-y-faire com o sintoma aponta para um sintoma no qual um sujeito possa se reconhecer (Soler, 1998c). Daí, esse savoir-y-faire implica a possibilidade de amar esse caráter sintomático irredutível de modo a se identificar com ele, como propóe Lacan.

Enfim, diferentemente de um esforço em evitar ou excluir a falta constitutiva à experiência analítica, a ideia de identificação com o sintoma conforme proposta por Lacan implica certa inclusão da falta no nível subjetivo através de uma identificação com o resíduo pulsional constante e intransponível do sintoma. Dito de outro modo, quando Lacan sugere que, no final de uma análise, o sujeito possa identificar-se ao sintoma, ele se refere a uma aceitação do gozo implicado no sintoma (Soler, 1998b).

Isso permite a Lacan alcançar definiçóes novas durante o último período de seu ensino ${ }^{2}$, promovendo a inclusão de elementos originais no regime conceitual da clínica analítica que redefinem temas como o final da análise e a cura. Essa redefinição implica, fundamentalmente, a noção de sintoma. Segundo Miller (2008-2009), nesse período final, Lacan:

amplia o conceito de sintoma, herdado de Freud, passível de ser eliminado, suspenso, conforme a expressão consagrada. Ela amplia o conceito freudiano a ponto de incluir nele essencialmente os restos sintomáticos referidos por Freud ao final da análise, levando-o a pensar a análise como sem fim em funçáo do que subsiste do sintoma. Pois bem, a segunda clínica psicanalítica é justamente aquela que reconfigura o conceito de sintoma sobre o modelo desses restos (Miller, 2008-2009). 
Como demonstrado, o sintoma em Lacan ganhou estatuto de modo de gozo singular do sujeito que implica sua forma de tratar o Real. Será nessa vertente que Lacan dará especificidade ao sintoma, escrevendo-o com uma grafia diferente: Sinthoma (Lacan, 1975-76/2005). Por ganhar em psicanálise uma função de sustentação e de forma de gozar tão particulares ao sujeito, a noção de sintoma, já distante da simples designaçáo de uma doença, recebe em Lacan, portanto, uma particularização:

Em psicanálise, quando falamos de sintoma, entendemos com isso um elemento passível de dissolver-se ou, supostamente, desaparecer, suspender-se, ao passo que sinthoma designa o elemento que não pode desaparecer, que é constante. Em outras palavras, a chamada nova clínica psicanalítica é uma teoria do incurável (Miller, 2008-2009).

A partir de então, a especificidade do sinthoma se alia ao fato de que o sinthoma tem a ver com o Real, distinto do symptôme enquanto formação do inconsciente (Lacan, 1975-76/2005). Se o que está em jogo é a centralidade do Real, Lacan dirá que "estamos engajados, e engajados a título do sinthoma. [...] é com o sinthoma que temos de nos haver" (Lacan, 1975-76/2005, p. 98). O Real, que não se rende ao tratamento simbólico, poderá, então, receber, nessa nova grafia, uma tentativa de demarcação.

$\mathrm{Na}$ experiência psicanalítica, orienta-se para um bom uso do sinthoma na prática da psicanálise, pois ele designa o que há de singular em cada indivíduo. Daí, vemos que a psicanálise relativiza o efeito terapêutico, pois a noção de sinthoma procura, mais do que nunca, iluminar o incurável na experiência psicanalítica. Para Miller (2008-2009), o sinthoma é o nome do incurável.

A revisão realizada, ainda que breve, sobre as proposiçóes lacanianas em torno do sintoma e de seu destino na experiência psicanalítica, esclarece que o tratamento por ela empreendido vislumbra favorecer saídas particulares de cada analisante. Assim, a operacionalidade que Lacan dá a essa noçóes, ao manipulá-las no interior da experiência analítica, permite que ganhem a função de demarcar os limites da eficácia terapêutica, pois derivam, justamente, do elemento incurável que se impóe na experiência. Concluímos com Lacan:

A análise não consiste em ser liberado de seus sinthomas [sinthomes], pois é assim que escrevo sintoma [symptôme]. A análise consiste em que se saiba porque se está emaranhado ${ }^{3}$ nele. [...] isso deixa traços. Porque isso deixa traços, isso tem consequências, que não é outra senão o sinto- 
ma [sinthome], e a análise consiste - às vezes há um progresso, na análise - em se dar conta de por que se tem esses sintomas [sinthomes] (Lacan, 1977-78).

\section{Referências}

Ferreira, R., \& Pimenta, A. (2003). O sintoma na medicina e na psicanálise: notas preliminares. Revista Médica de Minas Gerais, 13(3), 221-228.

Fingermann, D. (2005). O nome e o pior. In D. Fingermann, \& M. Dias. Por causa do pior (p. 21-40). São Paulo: Iluminuras.

Fink, B. (1998). O sujeito lacaniano: entre a linguagem e o gozo. Rio de janeiro: Jorge Zahar.

Forns, J., Batllo, J., \& Batllo, A. (1981). Semiologia médica e técnica exploratória. Rio de Janeiro: Guanabara Koogan.

Freud, S. (1976). Além do princípio do prazer. In S. Freud, Obras completas, v. 23. Rio de Janeiro: Imago. (Trabalho original publicado em 1920)

Freud, S. (1976). Conferência 34. In S. Freud, Obras completas, v. 22. Rio de Janeiro: Imago. (Trabalho original publicado em 1932)

Freud, S. (1976). Análise terminável e interminável. In S. Freud, Obras completas, v. 23. Rio de Janeiro: Imago. (Trabalho original publicado em 1937)

Lacan, J. (1964-65). Le séminaire, livre 12: problèmes cruciaux pour la psychanalyse. Paris: inédito.

Lacan, J. (1965-66). Le séminaire, livre 13: l'objet de la psychanalyse. Paris: inédito.

Lacan, J. (1966-67). Le séminaire, livre 14: la logique du fantasme. Paris: inédito.

Lacan, J. (1973). Le séminaire, livre 11: les quatre concepts fondamentaux de la psychanalyse. Paris: Seuil. (Trabalho original publicado em 1964)

Lacan, J. (1974-75). Le séminaire, livre 22: RSI. Paris: inédito.

Lacan, J. (1976-77). Le séminaire, livre 24: l'insu qui sait de l'une bévue s'aile a mourre. Paris: inédito.

Lacan, J. (1977-78). Le séminaire, livre 25: le moment de conclure. Paris: inédito.

Lacan, J. (1980). Monsieur A. In J. Lacan, Ornicar? (p. 17-20). Paris: Seuil.

Lacan, J. (1985). La tercera. In J. Lacan, Intervenciones y textos (p. 115-144). Buenos Aires: Manantial. (Trabalho original publicado em 1975)

Lacan, J. (1988). O seminário, livro 3: as psicoses. Rio de Janeiro: Jorge Zahar. (Trabalho original publicado em 1955-56)

Lacan, J. (1995). O seminário, livro 4: a relação de objeto. Rio de Janeiro: Jorge Zahar. (Trabalho original publicado em 1956-57) 
Lacan, J. (1998a). A significação do falo. In J. Lacan, Escritos (p. 692-703). Rio de Janeiro: Jorge Zahar. (Trabalho original publicado em 1958)

Lacan, J. (1998b). De nossos antecedentes. In J. Lacan, Escritos (p. 69-76). Rio de Janeiro: Jorge Zahar. (Trabalho original publicado em 1966)

Lacan, J. (1998c). Do sujeito enfim em questão. In J. Lacan, Escritos (p. 229-237). Rio de Janeiro: Jorge Zahar. (Trabalho original publicado em 1966)

Lacan, J. (1998d). Escritos. Rio de Janeiro: Jorge Zahar.

Lacan, J. (1998e). Função e campo da palavra e da linguagem. In J. Lacan, Escritos (p. 238324). Rio de Janeiro: Jorge Zahar. (Trabalho original publicado em 1953)

Lacan, J. (1998f). Para-além do princípio de realidade. In J. Lacan, Escritos (p. 83-84). Rio de Janeiro: Jorge Zahar. (Trabalho original publicado em 1936)

Lacan, J. (1998g). Subversão do sujeito e dialética do desejo no inconsciente freudiano. In J. Lacan, Escritos (p. 807-842). Rio de Janeiro: Jorge Zahar. (Trabalho original publicado em 1960)

Lacan, J. (1998h). Variantes do tratamento padrão. In J. Lacan, Escritos (p. 325-364). Rio de Janeiro: Jorge Zahar. (Trabalho original publicado em 1958)

Lacan, J. (2003a). Ato de fundação. In J. Lacan, Outros escritos (p. 235-247). Rio de Janeiro: Jorge Zahar. (Trabalho original publicado em 1964)

Lacan, J. (2003b). Proposição de 9 de outubro de 1967. In J. Lacan, Outros escritos (p. 248264). Rio de Janeiro: Jorge Zahar. (Trabalho original publicado em 1967)

Lacan, J. (2003c). Televisão. In J. Lacan, Outros escritos (p. 508-543). Rio de Janeiro: Jorge Zahar. (Trabalho original publicado em 1973)

Lacan, J. (2005). O seminário, livro 23: o sinthoma. Rio de Janeiro: Jorge Zahar. (Trabalho original publicado em 1975-76)

Lacan, J. (2008). O Seminário, livro 16: de um Outro ao outro. Rio de Janeiro: Jorge Zahar. (Trabalho original publicado em 1968-69)

Laia, S. (2008). O sintoma como problema e solução. aSEPHallus, Rio de Janeiro, 3(6), 64-72.

Merlet, A. (1998). Lacan médico. In A. Merlet, Lacan, você conhece? (p. 87-91). São Paulo: Cultura Editores Associados.

Miller, J.-A. (1997). Lacan elucidado - Palestras no Brasil. Rio de Janeiro: Jorge Zahar Editor. Miller, J.-A. (2005). Silet: os paradoxos da pulsão, de Freud a Lacan. Rio de Janeiro: Jorge Zahar. Miller, J.-A. (2008-2009). Coisas de fineza em psicanálise (Curso da orientação Lacaniana). Paris: inédito.

Soler, C. (1998a). Amar seu sintoma? In C. Soler, A psicanálise na civilização (p. 391-415). Rio de Janeiro: Contra Capa.

Soler, C. (1998b). O que posso esperar de uma psicanálise? In C. Soler, A psicanálise na civilização (p. 465-474). Rio de Janeiro: Contra Capa.

Soler, C. (1998c). Sintomas. Santafé de Bogotá: Asociación del Campo Freudiano de Colômbia. 
Teixeira, A. (2007). Dor de existir e lassidão do pensamento: por uma incursão ao Espinosa de Lacan. In A. Teixeira, A soberania do inútil e outros ensaios de psicanálise e cultura (p. 85103). São Paulo: Annablume.

\section{Notas}

${ }^{1} \mathrm{O}$ termo significa uma porta, uma entrada, mas também um limiar. Miller (1997) o concebe como lugar onde um organismo sobrevive numa tensão (Miller, 1997, p. 205). Encontram-se também definiçóes de umbral como uma regiáo de abismo ou inferno.

${ }^{2}$ Nomeado como "segunda clínica".

${ }^{3}$ Travado, enredado.

Recebido em 17 de outubro de 2011 Aceito para publicação em 12 de julho de 2012 